\title{
Influence of Solvent on the Component Composition and Antioxidant Properties of Apricot Cake (Prunus armeniaca L.) Extracts
}

\author{
A. S. Shakun $\mathbb{D}^{1},{ }^{1}$ V. I. Vorobyova ${ }^{\mathbb{D}},{ }^{1}$ O. E. Chygyrynets, ${ }^{1}$ and M. I. Skiba ${ }^{2}{ }^{2}$ \\ ${ }^{1}$ National Technical University of Ukraine "Igor Sikorsky Kyiv Polytechnic Institute", Kyiv,, Ukraine. Ave Peremogy 37, \\ Kiev 03056, Ukraine \\ ${ }^{2}$ Ukrainian State Chemical-Engineering University, Gagarin Ave. 8, Dnipro 49005, Ukraine
}

Correspondence should be addressed to A. S. Shakun; shakun.anastasiya.xd41@gmail.com

Received 17 November 2019; Revised 6 May 2020; Accepted 5 June 2020; Published 23 June 2020

Academic Editor: Massimiliano F. Peana

Copyright (C) 2020 A. S. Shakun et al. This is an open access article distributed under the Creative Commons Attribution License, which permits unrestricted use, distribution, and reproduction in any medium, provided the original work is properly cited.

Antioxidants of natural origin which are based on agroprocessing waste appear as substance with high performance properties. They have complicated structure and contain a complex of biologically active compounds. This is why research of the above is particularly relevant in current competitive market. When working with plant raw materials and isolation of valuable compounds, the urgent issue is the choice of the method (extraction method) and extractant, which will ensure a maximum release of chemically active compounds. Known solvents such as methanol, ethanol, hexane, diethyl ether, and mixtures thereof are usually used for recovery. The purpose of this research was to study the effect of selected nonpolar solvents on the phytochemical composition and the antioxidant capacity of Prunus armeniaca L. Extracts were obtained using ethanol, silicone, propan-2-ol, and mixtures of ethanol silicone and propan-2-ol with silicone. In the obtained extracts, identification of the sequestered chemically active compounds was carried out by means of chromatography, mass spectrometry, and IR and UV spectrometry, and the extracts were evaluated on antioxidant properties. Various extracts showed varying degrees of antioxidant activity in various test systems, depending on the concentration. Since various antioxidant compounds have different mechanisms of action, several methods have been used to evaluate the effectiveness of antioxidant extracts. The results showed that the test solvents play an important role in the extraction of the plant material into the component composition, as well as the antioxidant ability of Prunus armeniaca L.

\section{Introduction}

Apricot (Prunus armeniaca L.) is one of the most common fruit trees that grow on the territory of Ukraine, Greece, Turkey, with a harvest of about 160,000 tons per year. Consequently, its processing is accompanied by a large amount of waste (up to 20\%). The apricot cake is one of the major waste products from the apricot juice production that nowadays has a scarce use [1]. The resulting secondary resource is a pomace, which consists of fruit skins, cellulose, and seeds. It is considered as economically impractical product. However, considering the compositional profile of such industry by-products, especially the apricot cake which has been found to be one of the major sources of "green" compounds, their transformation into value-added products like natural antioxidant extracts is regarded as a promising option from economic and environmental perspective [2-4]. Agroindustrial by-products are cheap, abundant, and sustainable resources, which contain compounds with antioxidant $[4,5]$ and antimicrobial activities [6] that can be used for synthesis of nanoparticle $[7,8]$ and production of food additives $[9,10]$ and as a corrosion inhibitor for metals in corrosive media [11-13]. At the same time, the exploitation of waste materials generated by the agrifood processing industry and the use of antioxidant-rich plant extracts as food additives and/or nutraceuticals or active compounds for cosmetic products have attracted increasing interest $[14,15]$. This is because wastes of plant origin often 
contain natural antioxidants which are much safer than synthetic antioxidants and constitute a large source of valuable compounds. So, of course, a large number of synthetic antioxidants are used, the most popular of which are butylated hydroxytoluene (BHT) and butylated hydroxyanisole (BHA), but it is known that they are carcinogenic and have side effects [16].

At present, in the conditions of competitive market, the development of selection and introduction of highly effective antioxidants of natural origin based on waste from agroprocessing, which contains a complex of biologically active compounds, is especially relevant [17]. The literature shows the component composition of the apricot extract which is obtained by the most commonly known solvents, such as methanol and acetone. These extracts have antioxidant, antibacterial, and antifungal properties. However, solvents are not in favour of consumers or the environment due to their toxicity, high volatility, and nonrenewable properties, which entail a challenge for sustainable processes because they are strictly regulated by international legislations [18]. It is necessary to provide the most effective extraction conditions to obtain an extract with fully expressed antioxidant properties [19]. Antioxidative compounds in natural sources have different chemical properties, polarities, and stabilities which affect their solubility in organic solvents [20]. Type of solvent that is used in the extraction and recovery of antioxidative compounds from fruits was reported to be very influential due to the interaction between bioactive compounds, and the solvents are depending on their chemical structures and polarities. The choice of solvent is critical in the extraction process because it directly affects the selectivity of the extraction process and therefore affects the chemical composition and the functional properties of the final extract.

Thus, the aim of the study is to determine the effect of various solvents on the extraction efficiency of apricot cake (Prunus armeniaca L.) of phytochemically active compounds and the antioxidant capacity of the extracts obtained. Solvents of varying polarity were used: propan-2-ol, ethanol, silicone (cyclopentasiloxane), as well as systems of solvents such as silicone/ethanol and silicone/propan-2-ol.

\section{Materials and Methods}

2.1. Preparation of the Extract. The object of the study is a dry apricot cake, obtained by processing in the food industry. The apricot variety (Prunus armeniaca L.) is known locally as "Favorit," which is gathered (during July 2017) in two geographical regions of Ukraine (Kherson and Nikolaev). The technology of preparation of raw materials consists in grinding to particles of $5 \times 10^{-1} \mathrm{~mm}$ in size in order to increase the degree of cake's extra segmentation and the efficiency of mass transfer of biologically active components from plant material to the solvent.

Extraction was carried out by using microwave-assisted extraction with periodic mixing with a hydromodule of plant raw material and a solvent in ratio $2: 1$, followed by filtration at room temperature. To extract phytochemical compounds from the apricot cake Prunus armeniaca L., five solvents of different polarities were used: ethanol, propan-2-ol, decamethylcyclopentasiloxane (silicone (D5)), and propan-2-ol with decamethylcyclopentasiloxane $(1: 1)$ and ethanol decamethylcyclopentasiloxane $(1: 1)$. For further investigation of the preparation, the extracts were concentrated on a rotary evaporator until the solvent was completely removed.

\subsection{Determination of the Component Profile of Phytochemical Active Extract Compounds}

2.2.1. Gas Chromatography/Mass Spectrometry (GC-MS). Chemical composition and content of phytochemical compounds in the extract of the oilcake of the apricot were analyzed using the GC-mass spectrometry method on a gas chromatograph "FINIGAN FOCUS" with a mass spectrometric detector. The chromatographic conditions were as follows: capillary column HP-5MS, $1=30 \mathrm{~m}$, and $d=0.25 \mathrm{~mm}$; injector temperature, $+250^{\circ} \mathrm{C}$; temperature of the detector was $+280^{\circ} \mathrm{C}$; the thickness of the phase was $0.25 \mu \mathrm{m}$; carrier gas, helium; gas flow rate, $1.5 \mathrm{ml} / \mathrm{min}$; program $100^{\circ} \mathrm{C} \longrightarrow 10^{\circ} \mathrm{C} /$ $\min \longrightarrow 280^{\circ} \mathrm{C}$; range of masses, $30-500$ Dalton; split flow, $15 \mathrm{ml} / \mathrm{min}$; and the sample volume was $2 \mu \mathrm{l}$. The identification of the substances was carried out by comparing the retention time of the peaks on the chromatogram and the mass spectra of the separate components with the corresponding reference samples of the NIST-5 mass-spectrometer library and WILEY200T. Relative quantitative content of phytochemical components of the extract is calculated by the method of internal normalization of the areas of peaks without correcting the sensitivity coefficients [21].

2.2.2. Infrared Spectrometry. The IR spectrums of the extracts of apricot cake were recorded on a Jasco FT/IR-4000 FTIR spectrometer. The study conditions were as follows: the spectrum registration range is $4000-600 \mathrm{~cm}^{-1}$; resolution, $4 \mathrm{~cm}^{-1}$; the number of scans, automatically; scanning speed, $1 \mathrm{~mm} / \mathrm{s}$; and scanning mode, in transmitted light [22].

2.2.3. UV Spectrometry. Identification of the extracted compounds was carried out by using an ultraviolet ray spectrophotometer with two Shimizu UV-1601 rays from a PC (Shimadzu Corporation, Kyoto, Japan). UV-Vis spectrums were recorded between 200 and $800 \mathrm{~nm}$ [23].

2.2.4. Determination of Antioxidant Properties. The antioxidant activity of extracts of apricot cake obtained by ethanol, propan-2-ol, decamethylcyclopentasiloxane (D5), and their mixtures of propan-2-ol with decamethylcyclopentasiloxane $(1: 1)$ and ethanol with decamethylcyclopentasiloxane $(1: 1)$ was evaluated by methods of general antioxidant capacity and reducing force [24].

2.2.5. Total Antioxidant Assay. The total antioxidant capacity of the extracts was estimated by the phosphomolybdenum method [25]. The analysis is based on the 
reduction of Mo (VI) to Mo (V) with an extract and, as a result, the formation of a green phosphate complex/Mo $(\mathrm{V})$ in the presence of an acidic $\mathrm{pH}$. The ratio of the extract to the reagent is $1: 10$, that is, $0.5 \mathrm{ml}$ of the extract and ascorbic acid $(100 \mathrm{mg} / \mathrm{ml})$ mixed with $5 \mathrm{ml}$ of reagent $(0.6 \mathrm{M}$ sulfuric acid, $28 \mathrm{mM}$ sodium phosphate, and $4 \mathrm{mM}$ ammonium molybdate). The compensation solution contains $5 \mathrm{ml}$ of reagent and $0.5 \mathrm{ml}$ of the corresponding extractant, to which the extract was obtained. All containers were closed and incubated in a water bath at $95^{\circ} \mathrm{C}$ for 90 minutes. After cooling the samples to room temperature, the absorption capacity of the solutions was measured at $695 \mathrm{~nm}$ against compensation samples with the help of a UV-Vis spectrophotometer.

2.2.6. Ferric-Reducing Ability Power (FRAP). Recovery of $\mathrm{Fe}(\mathrm{III})$ was used as an indicator of electron donor activity. It is an important indicator of antioxidant properties. Extracts with a reducing potential react with potassium ferrocyanide $\left(\mathrm{Fe}^{3+}\right)$ to form potassium ferrocyanide $\left(\mathrm{Fe}^{2+}\right)$, which subsequently reacts with iron(III) chloride to form an iron complex, which has an absorption maximum at $700 \mathrm{~nm}$ [26]. To prepare the reaction solution, a different concentration of the test extract was used after the rotary evaporator $(g)$ $(0.005,0.01,0.015,0.02$, and 0.025$)$ in the appropriate solvent $(1 \mathrm{ml}), 1 \mathrm{ml}$ of phosphate buffer $(0.2 \mathrm{M}, \mathrm{pH} 6.6)$, and $1 \mathrm{ml}$ potassium ferrocyanide solution (1\%). The resulting solution was kept at $50^{\circ} \mathrm{C}$ for 20 minutes. To stop the reaction quickly, $1 \mathrm{ml}$ of three chloroacetic acid (10\%) was added and cooled under running water for 5 minutes. The resulting mixture was centrifuged at $3000 \mathrm{rpm}$ for 10 minutes. Then, an aliquot of $2 \mathrm{ml}$ was removed from the top layer of each solution, to which were added $2 \mathrm{ml}$ of distilled water and $0.4 \mathrm{ml}$ of ferric chloride solution $(0.1 \%)$. The absorption of the solution was measured at $700 \mathrm{~nm}$ with the introduction of a UV-Vis spectrophotometer. The increase in the ability of the reaction mixture to absorb radiation at the indicated wavelength indicates strong reducing properties of the extract. The results were expressed as mean \pm standard deviation (SD) from 2 repeated measurements with ascorbic acid as the reference solution.

2.2.7. Scavenging of DPPH Radicals. The method is based on the purification of DPPH by adding radical particles or an antioxidant that discolors the DPPH solution. The degree of color change is proportional to the concentration and efficiency of the antioxidants. Then, antioxidant activity is measured by the decrease in absorption at $517 \mathrm{~nm}$ [27].

Dry extract (RE) was dissolved in ethanol at various concentrations ranging from 0.01 to $0.5 \mathrm{mg} / \mathrm{ml}$. Each dilution $(0.5 \mathrm{ml})$ was mixed with $3 \mathrm{ml}$ of an ethanolic solution of DPPH $(0.1 \mathrm{mmol})$. The mixture was incubated in the dark at room temperature, and the absorbance of the DPPH solution was measured at $\lambda=517 \mathrm{~nm}$ (Jasco V-530, Japan) to $A_{\text {control }}$ and 30 minutes. After adding the extract $\left(\mathrm{A}_{\text {sample }}\right)$, in the blank, ethanol was used in place of the sample. Ascorbic acid, gallic acid, and BHT were used as a positive control. The ability to scavenge the DPPH free radical was calculated using the following equation: $\begin{aligned} \text { DPPH radical scavenging activity }(\%)= & \left(A_{\text {control }}-\frac{A_{\text {sample }}}{A_{\text {control }}}\right) \\ & \cdot 100 .\end{aligned}$

2.2.8. ABTS•+ Radical Cation Scavenging Assay. The method comprises a blue-green ABTS chromophore by the reaction of ABTS and potassium persulfate. This method is widely used. The ABTS cationic radical is generated by the oxidation of ABTS with potassium persulfate, and its reduction in the presence of hydrogen donor antioxidants is measured spectrophotometrically at $734 \mathrm{~nm}$. Bleaching analyzes the total antioxidant capacity of both lipophilic and hydrophilic substances.

ABTS assay [28] was applied with some modifications. A stock solution was prepared by adding $10 \mathrm{~mL}$ of $7.4 \mathrm{mM}$ ABTS solution to $10 \mathrm{~mL}$ of $2.6 \mathrm{mM} \mathrm{K}_{2} \mathrm{~S}_{2} \mathrm{O}_{8}$ and left at room temperature in the dark for $15 \mathrm{~h}$ and then stored at $-20^{\circ} \mathrm{C}$ until required. The working solution was freshly prepared by diluting $1 \mathrm{~mL}$ of stock solution with approximately $60 \mathrm{~mL}$ of ethanol to obtain an absorbance value of $1.1 \pm 0.02$ at $734 \mathrm{~nm}$ at the day of analysis. The extract was dissolved in ethanol at various concentrations ranging from 0.01 to $0.5 \mathrm{mg} / \mathrm{ml}$. Each dilution $(0.1 \mathrm{ml})$ was mixed with $3 \mathrm{ml}$ of reagent, and the absorbance of the ABTS cationic radical was measured at $\lambda=734 \mathrm{~nm}\left(A_{\text {control }}\right)$ and 60 minutes after adding the extract $\left(\mathrm{A}_{\text {sample }}\right)$. Ascorbic acid, gallic acid, and BHT were used as a positive control. The scavenging activity was calculated using the following equation:

$$
\text { ABTS radical scavenging activity }(\%)=\left(A_{\text {control }}-\frac{A_{\text {sample }}}{A_{\text {control }}}\right)
$$$$
\cdot 100 \text {. }
$$

2.3. Statistical Analysis. All samples were performed in triplicate and analyzed using one-way analysis of variance followed by a multiple Duncan test (IBM SPSS ${ }^{\circledR}$ Statistics version) for various concentrations. A $p$ value $<0.05$ was considered statistically significant.

\section{Results and Discussion}

3.1. Determination of the Component Composition of Extracts. The solvents which were used for the extraction of the apricot cake showed significantly different extraction capacities. A total of 50 components of different chemical structures present in an amount of more than $0.22 \%$ were isolated and identified by the chromatography-mass spectrometry method in an individual state $[1,29,30]$. Data of GC-MS extracts were obtained with ethanol, propan-2-ol, decamethylcyclopentasiloxane (silicone (D5)), and mixtures of propan-2-ol with decamethylcyclopentasiloxane $(1: 1)$ and ethanol with decamethylcyclopentasiloxane $(1: 1)$ (see Figure 1). 


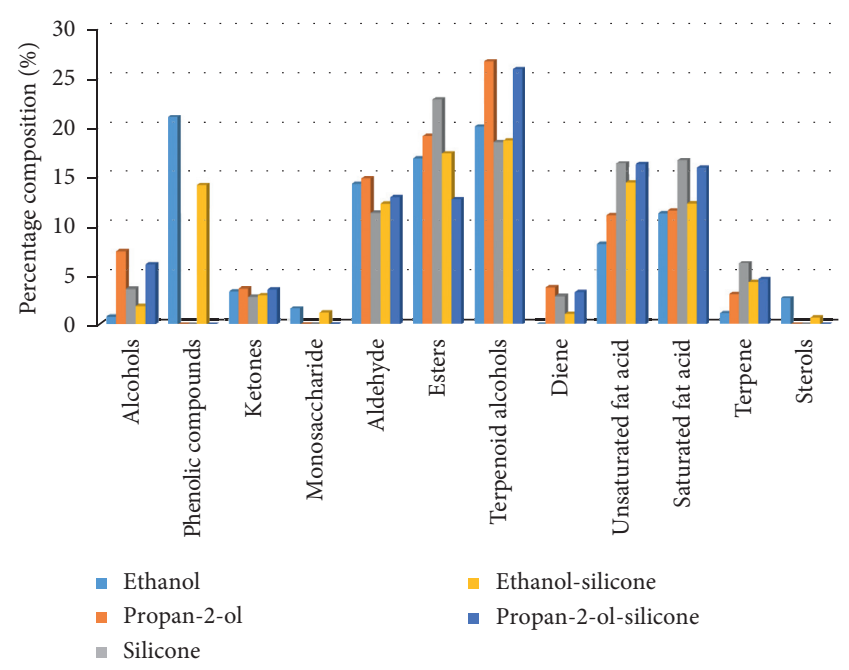

FIGURE 1: Component composition of the main classes of chemical compounds of the extract of apricot cake according to the results of chromatography-mass-spectral analysis.

The extract which is obtained by ethanol contains a large number of phenolic compounds, aldehydes, sugars, terpene alcohols, and flavonoids. Extract of propan-2-ol dry cake of apricot contains 38 separate components containing an increased content of terpene alcohols, which constitute more than $18 \%$ of the total number of identified substances in the apricot cake. The study of composition of the extract of silicone (D5) from apricot waste showed that it produces the same amount of compounds as propan-2-ol extract, but with different quantitative contents. The main number of identified compounds is duplicated by propan-2-ol extract. It also contains saturated and unsaturated aldehydes, alcohols, and ethers; however, terpenes compounds are present in a smaller percentage. Nevertheless, an increase in the amount of saturated and unsaturated fatty acids is observed in the silicone extract. The extract which was obtained with a mixture of solvents, namely, ethanol and silicone, showed the presence of all constituents of both the ethanol and the silicone extract. However, the content of fatty acids, terpene alcohols, ethers, and phenolic compounds has increased, indicating a more expedient extraction process.

The data from the diagrams below show that the extracts obtained by solvents, such as ethanol, 2-propanol, and silicone, and the mixtures of these solvents contain different contents of the main classes of chemical compounds (see Tables 1 and 2). A comparative analysis shows that the biological value of extracts obtained by a mixture of solvents due to the presence of the main classes of organic compounds does not decrease compared to extracts obtained by pure extractants.

The presence in the extract of the functional groups of the higher organic compounds is confirmed by an analysis of IR spectroscopy. For subjective interpretation of the IR analysis data, the extracts were divided into 2 systems depending on the extractant for ethanol-silicone and a mixture of ethanol-silicone $(1: 1)$ and propan-2-ol-silicone, and a mixture of propan-2-ol-silicone (1:1) (see Figures 2(a) and 2 (b) and Table 3 ).
In the spectrum, it is distinguished the absorption bands in the region of $3000-2800 \mathrm{~cm}^{-1}$-stretching vibrations and deformation vibrations at $1400-1340 \mathrm{~cm}^{-1}$, which indicates the presence of an intermolecular hydrogen bond. The presence of absorption bands in the range $2880-2650 \mathrm{~cm}^{-1}$ and $1480-1440 \mathrm{~cm}^{-1}$ (asymmetric valence vibrations $-\mathrm{CH}_{2}$ $\mathrm{CO})$ indicates the presence of aldehydes in the sample under study. The signal in the range $2940-2915 \mathrm{~cm}^{-1}$ and $1680-1640 \mathrm{~cm}^{-1}$ corresponds to unsaturated compounds from the double bond, and at 2853, the aliphatic groups $\mathrm{CH}_{2}$ fluctuate. Ketones are determined with a fluctuation in the range of $1750-1740 \mathrm{~cm}^{-1}$. Absorption bands of $1725-1700 \mathrm{~cm}^{-1}$ and $1320-1210 \mathrm{~cm}^{-1}$, where the deformation vibrations of - $\mathrm{COOH}$ occur, indicate compounds with a carboxyl group [31]. The presence of a vibration at $1440-1395 \mathrm{~cm}^{-1}$ is responsible for the presence of fatty acids in the extract. There are also absorption bands in the range $1380-1378 \mathrm{~cm}^{-1}$, 1175-1125, and $671 \mathrm{~cm}^{-1}$, characteristic for vibrations of aromatic structures. Asymmetric vibrations of the -C-O-Cgroup in the absorption band $1280-1150 \mathrm{~cm}^{-1}$ confirm the presence of esters and lactones.

Spectroscopic UV-Vis method is one of the main methods of qualitative determination of chemical compounds that are contained in extracts. The sample of the qualitative profile of the UV spectrum of the extract was carried out at a wavelength of 200-800 nm (see Figure 3).

For the correct reproduction of ultraviolet spectroscopic data, both extracts and the solvents themselves were studied. After analyzing the spectrum obtained in the investigated region, it was found that the reliability of the spectrum is actively influenced by the solvent, so spectroscopy of samples with solvent compensation established in the subtraction channel was performed.

Different compounds have their characteristic wavelength of maximum absorption. The absorption spectrum for the ethanol extract has peaks with a maximum of 330 and $362 \mathrm{~nm}$, which corresponds to compounds of phenolic origin and peak at 416 , which indicates the presence of esters of complex structure. For the silicone extract, peaks at $244 \mathrm{~nm}$ and $271 \mathrm{~nm}$ were found to confirm the presence of fatty acids in their composition. The extract which was obtained with a mixture of ethanol and cyclopentasiloxane has peaks of the respective substances in the extract, which was made with individual solvents. The peak at 264 and $291 \mathrm{~nm}$ shows that there is the presence of fatty acids, respectively; peaks at 355 and 381 indicate phenolic compounds in the extract, and at $426 \mathrm{~nm}$, ethers are observed. For the propan-2-ol extract, the peak values are $313 \mathrm{~nm}$ and $370 \mathrm{~nm}$ and indicate the terpenoid compounds and their derivatives. According to GCMS, the extract contains the highest content of terpenoid compounds, namely, geraniol and nerolidol. On the UV spectrum of the extract which was obtained from a mixture of 2-propanol and decamethylcyclopentasiloxane, two peaks at $248 \mathrm{~nm}$ and $319 \mathrm{~nm}$ show the prevalence of compounds from the class of fatty acids and terpenoids.

Analyzing the results of the three methods for identifying individual substances in extracts that were obtained from polypolar solvents, it can be concluded that phenolic compounds and flavonoid compounds are only removed by 
TABLE 1: Component profile of extracts of pomace apricot.

\begin{tabular}{|c|c|c|c|c|c|c|}
\hline \multirow{2}{*}{$\mathrm{RT}(\min )$} & \multirow{2}{*}{ Name of the compound } & \multicolumn{5}{|c|}{ Quantitative ratio (\%) } \\
\hline & & Ethanol & Propan-2-ol & Silicone (D5) & Ethanol-D5 & Propan-2-ol-D5 \\
\hline 4.04 & Hexanol & - & 2.67 & 0.34 & 0.94 & 1.79 \\
\hline 5.34 & (Z)-3-Hexenol & 0.80 & 0.76 & - & 0.62 & 0.57 \\
\hline 6.81 & Gallic acid & 4.19 & - & - & 3.56 & - \\
\hline 7.23 & 2-Hexanone & 1.05 & 1.03 & 0.94 & 1.39 & 1.00 \\
\hline 7.69 & Manose & 0.24 & - & - & 0.22 & - \\
\hline 8.01 & 3-Hexanone & 1.72 & 0.54 & 0.53 & 1.46 & 0.63 \\
\hline 9.58 & Hexanal & 1.28 & 1.32 & 0.79 & 1.10 & 1.21 \\
\hline 10.06 & Benzaldehyde & 3.18 & 0.94 & 1.92 & 3.75 & 1.06 \\
\hline 11.96 & Heptanal & 0.64 & 2.18 & 1.02 & 0.89 & 1.76 \\
\hline 12.71 & Phenylacetaldehyde & 1.73 & 3.29 & 3.06 & 3.29 & 3.46 \\
\hline 14.01 & (E)-2-Hexenyl acetate & 1.06 & 2.78 & 0.53 & 0.67 & 2.37 \\
\hline 14.12 & Chlorogenic acid & 3.82 & - & - & 1.78 & - \\
\hline 14.37 & $\gamma$-Octalactone & 0.71 & 2.03 & 1.98 & 0.76 & 1.99 \\
\hline 14.43 & Isoborneol & 0.43 & 1.03 & 1.59 & 0.57 & 1.07 \\
\hline 14.92 & $\beta$-Cyclocitral & 3.24 & 5.17 & 4.27 & 3.56 & 5.06 \\
\hline 15.03 & Fructosa & 0.27 & - & - & 0.21 & - \\
\hline 15.42 & $(2 \mathrm{E}, 4 \mathrm{E})$-Deca-2,4-dienal & - & 3.65 & 2.81 & 0.74 & 3.19 \\
\hline 15.74 & Caffeic acid & 2.71 & - & - & 1.65 & - \\
\hline 15.86 & Nerol & 3.09 & 3.02 & 4.74 & 3.15 & 4.25 \\
\hline 16.74 & $\alpha$-Linolenic acid & 1.94 & 0.63 & 4.94 & 3.71 & 2.17 \\
\hline 16.98 & D-Glucose & 0.98 & - & - & 0.94 & - \\
\hline 17.06 & Geraniol & 3.49 & 8.54 & 4.52 & 4.91 & 6.94 \\
\hline 17.29 & Linoleic acid & 3.29 & 4.38 & 5.34 & 4.02 & 5.18 \\
\hline 18.24 & Palmitic acid & 2.61 & 5.49 & 5.98 & 3.34 & 5.63 \\
\hline 18.32 & Linalool & 3.32 & 3.06 & 2.71 & 2.80 & 2.97 \\
\hline 18.94 & 1-Tetradecanoic acid & 3.29 & - & 4.35 & 3.54 & 2.01 \\
\hline 19.60 & Stearic acid & 5.71 & 7.10 & 7.74 & 5.84 & 6.11 \\
\hline 19.62 & (9Z)-Octadec-9-enoic acid & 4.01 & 6.29 & 6.98 & 5.13 & 6.59 \\
\hline 20.67 & Isololiolide & 2.04 & 2.05 & 2.18 & 1.96 & 2.07 \\
\hline 20.91 & $\delta$-Decalactone & - & 2.87 & 1.91 & 0.82 & 2.52 \\
\hline 21.09 & (Z)-3-Hexenyl butanoate & 2.91 & 1.77 & 1.24 & 1.79 & 1.36 \\
\hline 21.23 & Palmitoleic acid & - & - & 0.56 & - & 0.54 \\
\hline 22.18 & $\alpha$-Copaene & 3.09 & 4.02 & 4.53 & 3.22 & 4.38 \\
\hline 23.07 & Quercetin & 7.10 & - & - & 6.19 & - \\
\hline 23.08 & 4-Terpineol & 6.24 & 4.98 & 5.54 & 5.72 & 4.61 \\
\hline 23.54 & $\alpha$-Terpineol & 6.61 & 5.98 & 5.82 & 5.94 & 5.47 \\
\hline 23.82 & $\beta$-Ionone & 0.47 & 1.97 & 2.24 & 0.68 & 1.79 \\
\hline 24.16 & Catechin & 2.94 & - & - & 1.79 & - \\
\hline 24.48 & $p$-Coumaric acid & 1.94 & - & - & 1.03 & - \\
\hline 26.32 & Dihydro-5-octyl-2(3H)-furanone & 0.65 & 0.54 & 3.91 & 0.98 & 1.84 \\
\hline 26.79 & Nerolidol & 2.52 & 8.54 & 4.30 & 2.82 & 7.54 \\
\hline 27.21 & Farnesol & - & 1.38 & 0.69 & - & 0.87 \\
\hline 28.44 & Isoquercetin & 1.74 & - & - & 1.17 & - \\
\hline 29.51 & Stigmasterol & 0.43 & - & - & 0.37 & - \\
\hline 30.08 & Eicosanoic acid & 0.39 & - & - & - & - \\
\hline 30.92 & $\beta$-Sitosterol & 2.13 & - & - & 0.98 & - \\
\hline
\end{tabular}

TABLE 2: Comparative characteristics of the percentage content of the main classes of extracts obtained by different solvents.

\begin{tabular}{|c|c|c|c|c|}
\hline \multirow{3}{*}{ Basic classes of chemical compounds } & \multicolumn{4}{|c|}{ Content of the main classes of organic compounds (\%) } \\
\hline & Ethanol & Propan-2-ol & & \\
\hline & \multicolumn{2}{|c|}{ Ethanol-D5 } & \multicolumn{2}{|c|}{$\begin{array}{l}\text { Silicone (D5) } \\
\text { Propan-2-ol-D5 }\end{array}$} \\
\hline \multirow{2}{*}{ Phenolic compounds } & 24.44 & 0 & & 0 \\
\hline & & & 0 & \\
\hline \multirow{2}{*}{ Ketones } & 3.24 & 3.54 & & 3.71 \\
\hline & & & 3.42 & \\
\hline \multirow{2}{*}{ Aldehyde } & 10.07 & 12.90 & & 11.06 \\
\hline & & & 12.55 & \\
\hline \multirow{2}{*}{ Terpenoid alcohols } & 25.70 & 36.53 & & 29.91 \\
\hline & & & 33.72 & \\
\hline \multirow{2}{*}{ Esters } & 5.33 & 9.99 & & 9.57 \\
\hline & & & 10.08 & \\
\hline
\end{tabular}




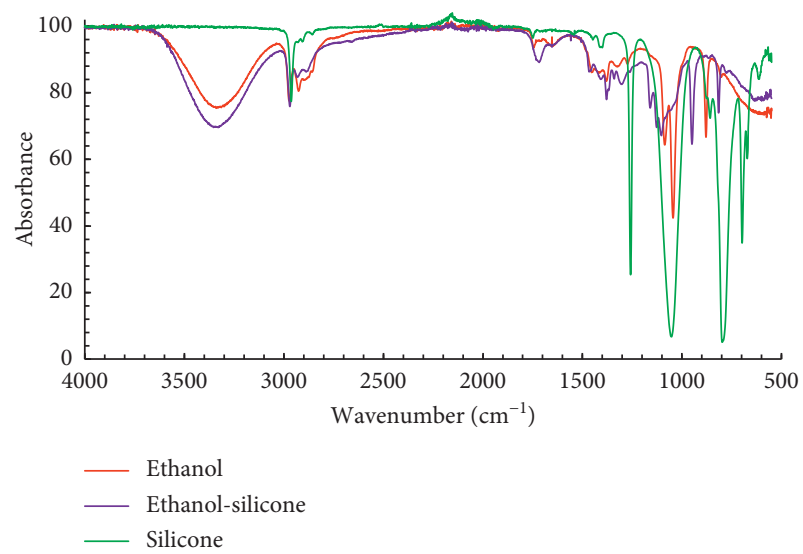

(a)

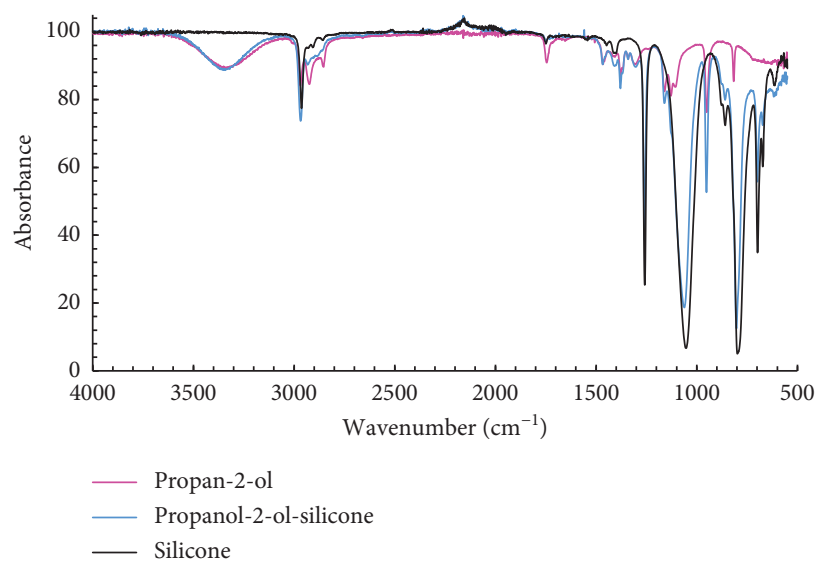

(b)

FIGURE 2: (a) IR spectrum of the extract of apricot cake obtained by ethanol, silicone, and ethanol-silicone; (b) IR spectrum of the extract of apricot cake obtained by 2-propanol, silicone, 2-propanol-silicone.

TABLE 3: Absorption bands $\left(\mathrm{cm}^{-1}\right)$ in the IR spectrum of apricot flint extracts.

\begin{tabular}{|c|c|c|c|c|c|c|}
\hline \multirow{2}{*}{ Wavetype } & \multirow{2}{*}{ Frequency $\left(\mathrm{cm}^{-1}\right)$} & \multicolumn{5}{|c|}{ Extracts } \\
\hline & & 2-Propanol & 2-Propanol silicone & Ethanol-silicone & Ethanol & Silicone \\
\hline$\nu \mathrm{OH}$ & $3636-3150$ & 3334 & 3339 & 3329 & 3330 & \\
\hline$\nu \mathrm{CH}$ & $2880-2650$ & 2968 & 2967 & 2969 & 2971 & 2962 \\
\hline$v_{\mathrm{as}} \mathrm{CH}_{2}$ & 2940-2915 & 2924 & 2930 & 2927 & 2925 & - \\
\hline$v_{\mathrm{s}} \mathrm{CH}_{2} \mathrm{OH}$ & $330-2500$ & - & - & 2885 & - & 2905 \\
\hline$\nu_{\mathrm{as}} \mathrm{CH}_{2}$ & $2857-2853$ & 2853 & - & - & - & - \\
\hline$\nu \mathrm{CH}_{2} \mathrm{COOR}$ & $1750-1735$ & - & - & - & - & 1753 \\
\hline$\nu \mathrm{C}=\mathrm{O}$ & $1750-1740$ & 1745 & 1746 & - & 1743 & - \\
\hline$\delta \mathrm{COOH}$ & $1725-1700$ & - & - & 1718 & - & - \\
\hline$\nu \mathrm{C}=\mathrm{C}$ & $1680-1640$ & 1654 & - & 1649 & 1647 & - \\
\hline$v_{\mathrm{as}} \mathrm{CH}_{2} \mathrm{CO}$ & $1480-1440$ & 1465 & 1468 & 1459 & 1452 & - \\
\hline$\delta \mathrm{CH}_{2} \mathrm{COOH}$ & $1440-1395$ & 1409 & 1407 & 1405 & - & 1399 \\
\hline$\delta \mathrm{OH}$ & $1400-1340$ & 1379 & 1379 & 1379 & 1388 & - \\
\hline$\delta_{\mathrm{as}} \mathrm{CH}_{3}$ & $1380-1378$ & - & - & - & 1380 & - \\
\hline$\delta_{\mathrm{as}} \mathrm{OH}$ & $1410-1310$ & 1321 & 1321 & 1319 & 1320 & - \\
\hline$\nu \mathrm{CO}$ & $1320-1210$ & 1300 & 1304 & 1299 & 1273 & - \\
\hline$v_{\mathrm{as}} \mathrm{COC}$ & $1280-1150$ & - & 1260 & - & - & 1257 \\
\hline$\delta \mathrm{CH}$ & $1175-1125$ & 1159 & 1159 & 1157 & - & - \\
\hline$\delta \mathrm{OH}$ & $1170-1100$ & 1128 & - & 1112 & - & - \\
\hline$\nu \mathrm{COH}$ & $1125-1085$ & 1103 & 1066 & 1103 & 1088 & - \\
\hline$\nu \mathrm{COH}$ & $1085-1050$ & - & - & - & - & 1052 \\
\hline$\delta \mathrm{COH}$ & $955-860$ & 950 & 952 & 951 & 879 & 862 \\
\hline$\nu \mathrm{COOH}$ & $920-800$ & - & 857 & - & - & - \\
\hline$\delta \mathrm{CHO}$ & $975-780$ & 815 & 801 & 816 & 803 & 796 \\
\hline$\delta \mathrm{OH}$ & $750-650$ & - & 689 & 753 & - & 697 \\
\hline$\delta \mathrm{C}=\mathrm{COH}$ & $674-671$ & - & 671 & - & - & 671 \\
\hline
\end{tabular}

solvents such as ethanol and a mixture of silicone-ethanol (1: 1 ). In the propan-2-ol extract, the amount of terpene alcohols and aldehydes predominates, whereas the silicone extract contains a large content of fatty acids and esters. Extracts that are obtained with a mixture of solvents have an average content of all the components of the extracts described by individual solvents.

3.2. Antioxidant Activity. Extraction with solvents is frequently used for the isolation of antioxidant compounds, and both extraction yield and antioxidant activity of the extracts have a strong relationship with the solvent which was used [32]. Antioxidant activity of plant extracts is analyzed using several methods in the complex that could fully reflect their quality. In this study, the antioxidant activity of the extracts was evaluated using four different assays.

3.3. Assessment of Total Antioxidant Capacity. The total antioxidant activity was measured by the phosphomolybdenum method. This method of analysis is considered to be simple, but informative for antioxidant properties. In addition, it is quantitative, so the antioxidant activity is 


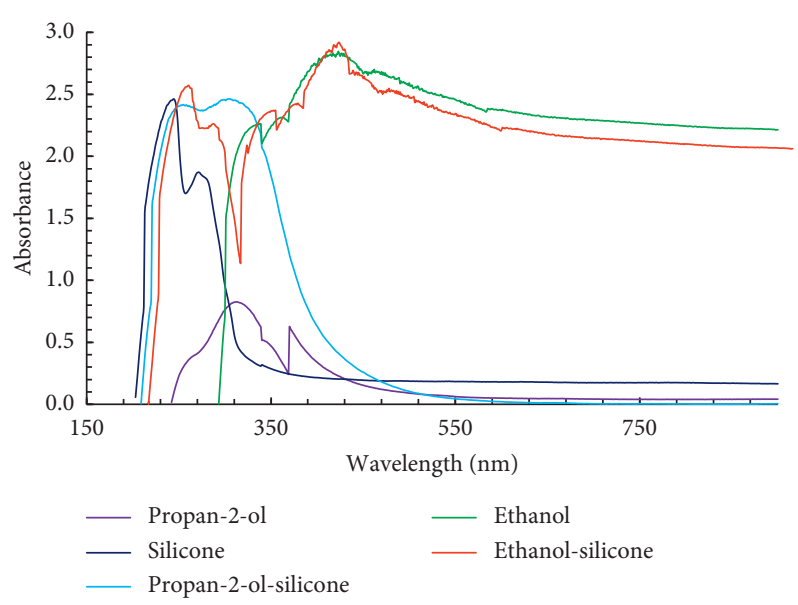

FIgURE 3: Spectrum of ultraviolet absorption of extracts of apricot cake.

TABLE 4: The total antioxidant capacity of extracts obtained using various solvents.

\begin{tabular}{lccccc}
\hline Plant extract & \multicolumn{4}{c}{ Total antioxidant capacity (mg of ASA/g extract) } \\
\hline \multirow{2}{*}{ Extract of apricot pomace } & Ethanol & D5 & Ethanol-D5 & Propan-2-ol & Propan-2-ol-D5 \\
& $460.86 \pm 2.6$ & $119.56 \pm 6.1$ & $447.62 \pm 7.4$ & $107.72 \pm 4.2$ & $123.78 \pm 2.9$ \\
\hline
\end{tabular}

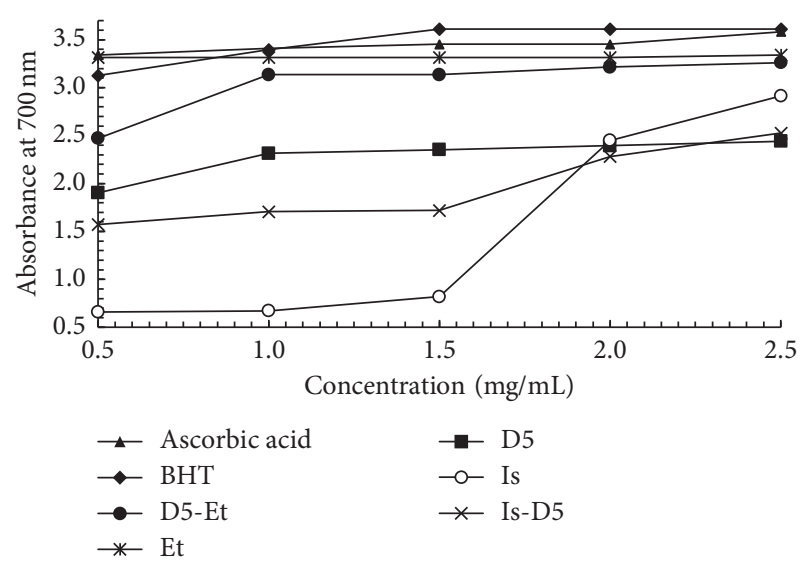

FIGURE 4: Reducing power of extracts obtained by various solvents.

expressed as the amount of equivalent ascorbic acid ( $\mathrm{mg} / \mathrm{g}$ of plant extract) (see Table 4).

On the basis of Table 4, it can be argued that the ethanol extract has more pronounced antioxidant properties among all the test samples $(460.86 \pm 2.6)$, the extract which was obtained by the mixture of solvents of silicone and ethanol $(447.62 \pm 7.4)$ is not inferior in antioxidant properties of the extract of ethanol, and the extract which was obtained by silicone (199.56 \pm 6.1$)$, propan-2-ol $(201.72 \pm 4.2)$, and their mixture $(199.78 \pm 2.9)$ showed slightly lower results. But antioxidant activity is average and allows their use as antioxidants in various areas of chemical technology. The total antioxidant activity of apricot cake extracts is the result of individual activities of each of the antioxidant compounds present such as tocopherols, carotenoids, and phenolic compounds, the latter being the major phytochemical responsible for antioxidant activity of plant materials $[33,34]$. Moreover, these compounds render their effects via different mechanisms such as radical scavenging, metal chelation, inhibition of lipid peroxidation, and quenching of singlet oxygen to act as antioxidants. Even if a sample exhibits high activity with one of these methods, it does not always show similar good results with all other methods. Therefore, it is essential to evaluate samples accurately by several methods.

3.4. Reducing Power. The reducing power is associated with an antioxidant effect and can serve as a significant reflection of antioxidant activity. Compounds with reducing ability show that they are electron donors that have the ability to reduce oxidized intermediates of lipid peroxidation processes, and they can act as primary and secondary antioxidants. A higher absorption of the reaction mixture indicates a higher reductive potential.

Figure 4 shows the concentration-absorption curves for reflecting the presence of restorative force of the extracts. The recovery ability of extracts increased with increasing concentrations. Extracts showed a sufficiently high antioxidant activity.

The highest reduction ability in comparison with known powerful antioxidants such as ascorbic acid and BHT has an extract obtained by ethanol [10]. Its reducing ability does not depend on concentration, which is economically feasible in the chemical industry. In the extract from the mixture of solvents of silicone and ethanol, obtained in the ratio $(1: 1)$, slightly less reducing force is observed, but at a concentration of $1 \mathrm{mg} / \mathrm{ml}$ and higher, it increases and remains constant, which indicates the stability of the result of the renewable ability. For the silicone extract, the reducing 
TABLE 5: Free radical scavenging activity of extracts obtained using various solvents by DPPH method.

\begin{tabular}{|c|c|c|c|c|c|c|c|c|}
\hline \multirow{2}{*}{$\mathrm{mg} / \mathrm{ml}$} & \multicolumn{8}{|c|}{ Percent decolorization at $517 \mathrm{~nm}($ mean \pm SD) $(\%)$} \\
\hline & Ethanol & D5 & Ethanol-D5 & Propan-2-ol & Propan-2-ol-D5 & Ascorbic acid & Gallic acid & BHT \\
\hline 0.01 & $29.2 \pm 2.7$ & $12.5 \pm 0.7$ & $28.4 \pm 1.6$ & $12.7 \pm 0.2$ & $11.9 \pm 0.6$ & $42.8 \pm 1.8$ & $38.3 \pm 0.4$ & $48.5 \pm 1.5$ \\
\hline 0.05 & $36.1 \pm 0.7$ & $15.6 \pm 1.0$ & $40.7 \pm 1.2$ & $16.3 \pm 1.3$ & $20.7 \pm 1.3$ & $49.5 \pm 2.3$ & $41.6 \pm 1.5$ & $52.1 \pm 0.6$ \\
\hline 0.10 & $46.7 \pm 1.6$ & $23.9 \pm 2.1$ & $47.3 \pm 0.5$ & $25.8 \pm 0.9$ & $27.2 \pm 0.8$ & $53.1 \pm 1.1$ & $47.6 \pm 1.8$ & $57.1 \pm 1.9$ \\
\hline 0.20 & $58.9 \pm 1.1$ & $35.7 \pm 0.9$ & $58.8 \pm 1.0$ & $36.4 \pm 0.3$ & $38.8 \pm 1.5$ & $60.6 \pm 1.2$ & $62.8 \pm 2.3$ & $63.7 \pm 0.7$ \\
\hline 0.35 & $71.5 \pm 0.9$ & $41.9 \pm 1.6$ & $74.2 \pm 1.8$ & $48.5 \pm 1.8$ & $45.3 \pm 0.9$ & $79.7 \pm 1.8$ & $72.4 \pm 1.3$ & $77.2 \pm 1.6$ \\
\hline 0.50 & $87.6 \pm 1.4$ & $47.8 \pm 1.2$ & $89.1 \pm 0.6$ & $51.3 \pm 1.3$ & $52.1 \pm 1.7$ & $94.1 \pm 1.1$ & $84.9 \pm 1.8$ & $84.3 \pm 0.3$ \\
\hline
\end{tabular}

TABle 6: Scavenging activity apricot cake extracts against ABTS radical at different concentrations.

\begin{tabular}{|c|c|c|c|c|c|c|c|c|}
\hline \multirow{2}{*}{$\mathrm{mg} / \mathrm{ml}$} & \multicolumn{8}{|c|}{ Scavenging activity $(\%)($ mean \pm SD) } \\
\hline & Ethanol & D5 & Ethanol-D5 & Propan-2-ol & Propan-2-ol-D5 & Ascorbic acid & Gallic acid & BHT \\
\hline 0.01 & $14.1 \pm 1.6$ & $5.1 \pm 1.2$ & $18.4 \pm 1.5$ & $7.6 \pm 2.1$ & $5.9 \pm 1.5$ & $40.5 \pm 2.0$ & $44.8 \pm 1.5$ & $32.1 \pm 1.8$ \\
\hline 0.05 & $21.7 \pm 2.3$ & $9.7 \pm 1.8$ & $25.8 \pm 0.4$ & $11.2 \pm 1.4$ & $10.3 \pm 0.8$ & $52.3 \pm 1.5$ & $53.5 \pm 2.2$ & $40.5 \pm 2.0$ \\
\hline 0.10 & $34.7 \pm 1.8$ & $16.2 \pm 2.1$ & $35.2 \pm 1.3$ & $16.9 \pm 0.5$ & $16.7 \pm 1.7$ & $58.6 \pm 1.1$ & $57.8 \pm 1.8$ & $47.3 \pm 1.3$ \\
\hline 0.20 & $42.6 \pm 1.8$ & $20.1 \pm 1.5$ & $45.3 \pm 1.8$ & $25.7 \pm 1.3$ & $22.7 \pm 0.3$ & $68.5 \pm 0.6$ & $65.4 \pm 1.3$ & $56.4 \pm 2.0$ \\
\hline 0.35 & $56.9 \pm 1.4$ & $24.8 \pm 1.1$ & $58.2 \pm 1.1$ & $27.4 \pm 0.4$ & $26.9 \pm 1.5$ & $76.4 \pm 1.5$ & $72.6 \pm 1.9$ & $69.5 \pm 1.7$ \\
\hline 0.50 & $74.1 \pm 1.3$ & $30.3 \pm 1.4$ & $75.8 \pm 0.3$ & $32.9 \pm 1.7$ & $31.6 \pm 1.5$ & $83.6 \pm 2.3$ & $78.9 \pm 2.0$ & $79.2 \pm 0.5$ \\
\hline
\end{tabular}

Data are mean \pm SD of three determinations.

ability is slightly lower than that in the above extracts and also has a stable renewable ability at concentrations above $1 \mathrm{mg} / \mathrm{ml}$. Propan-2-ol extract and extract obtained with a mixture of propan-2-ol and silicone have a reducing ability, which depends significantly on the concentration and increases with its increase.

Because of their high reduction ability, these extracts exhibit a reductive potential and can serve as strong electron donors, leading to the completion of a radical chain reaction.

3.5. DPPH Radical Scavenging Assay. Free radical removal activity is determined by the DPPH assay. The DPPH radical is removed by polyphenolic compounds through the donation of hydrogen and the formation of reduced DPPH. Substances that are capable of performing this reaction can be considered as antioxidants and radical scavengers. Antioxidants usually react with $\mathrm{DPPH}$ at a very high rate. The well-known antioxidant compounds, ascorbic acid, gallic acid, and BHT, were used as a positive control. Extracts showed a concentration-dependent antiradical activity by inhibiting DPPH radical (see Table 5).

From the data obtained, it can be concluded that, with increasing concentration, the antiradical activity of the test sample increases in a different trend. The highest antiradical activity, at a concentration of $0.5 \mathrm{mg} / \mathrm{ml}$, was shown by an extract which was obtained by a mixture of silicone and ethanol $(89.1 \pm 0.6)$; this sample can act along with ascorbic acid, not inferior to its properties. At a studied concentration of $0.01 \mathrm{mg} / \mathrm{ml}$, the extract which was obtained by ethanol is the most effective $(29.2 \pm 2.7)$. The antiradical activity of the extracts of apricot gum obtained by different solvents decreases in the series: ethanol-D5 > ethanol > propan-2-ol-D5 $>$ D5 > propan-2-ol.

It should be noted that solvent properties such as polarity, $\mathrm{pH}$, hydrogen bond accepting ability, or capacity to donate hydrogen atoms to free radicals are factors that can influence the mechanism of free radical scavenging reactions, greatly affecting the kinetics and the overall results of antioxidant capacity assays [34]; therefore, potential interferences with the free radical scavenging mechanism may explain the lower antioxidant capacity values of some extracts as obtained here. Although no direct correlation can be drawn between component composition of the extract and the antioxidant potential of the extracts, the results suggest that the solvent which was used for extraction may have different impacts on the antioxidant capacity of the extracts.

3.6. ABTS•+ Radical Cation Scavenging Assay. Along with the DPPH method, the ABTS radical scavenging method is one of the most extensively used methods for antioxidant assays for plant samples [35]. Antioxidants or radical scavenger in the added sample causes suppression of this color production to a degree that is proportional to their concentration (see Table 6). The generation of ABTS radical is allowed to proceed until a stable color of ABTS radical occurs. Antioxidants, which have scavenging activity, therefore, decolorizes a mixture of ABTS radical, thus giving an index of their antioxidant capacity.

The extracts demonstrated a wide range of ABTS $\bullet+$ scavenging activities from 83.6 to $5.1 \%$. Extracts with ethanol-D5 were the most efficient ABTS•+ scavengers, followed by those with ethanol and propan-2-ol. However, extracts with D5 and propan-2-ol- D5 were less effective in minimizing lipid oxidation. It can be concluded that extracts obtained using solvents with high polarity were significantly more effective scavengers of radicals than extracts which were obtained using solvents with low polarity, which indicates that antioxidants or active compounds of different polarities may be present in 
extracts with high antioxidant capacity. Change in the polarity of a solvent alters its ability to dissolve a selected group of antioxidant compounds and influences activity estimation.

ABTS $\bullet+$ absorption data suggest that components in extracts are capable of absorbing free radicals through an electron/hydrogen donation mechanism and should be able to protect sensitive matrices from oxidative degradation mediated by free radicals.

\section{Conclusions}

The extract of apricot pomace contains a considerable amount of organic compounds with antioxidant potential, which can be extracted using organic solvents with different polarities. The set of extractable compounds is determined by the type of solvent. So, according to the results of quantitative GC-MS analysis, it was shown that the extract obtained using a mixture of silicone/ethanol gives a wide range of phenolic compounds (24.4\%), terpene alcohols $(25.70 \%)$, and aldehydes (10.07\%). The maximum antioxidant effectiveness (DPPH method, 89.1\%, and ABTS method, 75.8\%) was established for extract obtained with ethanol-silicone mixtures, that is, a mixture of polar ethanol with nonpolar silicone allowed to extract a wide range of compounds responsible for antioxidant activity. The results which were obtained demonstrated the potential of the apricot pomace as an economical source of antioxidant and phytochemical compounds for the food or cosmetic industries.

\section{Data Availability}

The experimental part was performed with agreement of all coauthors.

\section{Conflicts of Interest}

The authors declare that they have no conflicts of interest.

\section{References}

[1] F. Gurrieri, J.-M. Audergon, G. Albagnac, and M. Reich, "Soluble sugars and carboxylic acids in ripe apricot fruit as parameters for distinguishing different cultivars," Euphytica, vol. 117, no. 3, pp. 183-189, 2001.

[2] H. Bae, S. K. Yun, J. H. Jun et al., "Assessment of organic acid and sugar composition in apricot, plumcot, plum, and peach during fruit development," Journal of Applied Botany and Fruit Quality, vol. 87, pp. 24-29, 2014.

[3] E. B. Akin, I. Karabulut, and A. Topcu, "Some compositional properties of main Malatya apricot (Prunus armeniaca L.) varieties," Food Chemistry, vol. 107, no. 2, pp. 939-948, 2008.

[4] J. Esteban and M. Ladero, "Food waste as a source of valueadded chemicals and materials: a biorefinery perspective," International Journal of Food Science \& Technology, vol. 53, no. 5, pp. 1095-1108, 2018.

[5] G.-F. Deng, X. Lin, X.-R. Xu, L.-L. Gao, J.-F. Xie, and H.-B. Li, "Antioxidant capacities and total phenolic contents of 56 vegetables," Journal of Functional Foods, vol. 5, no. 1, pp. 260-266, 2013.
[6] D. Yigit, N. Yigit, and A. Mavi, "Antioxidant and antimicrobial activities of bitter and sweet apricot (Prunus armeniaca L.) kernels," Brazilian Journal of Medical and Biological Research, vol. 42, pp. 346-352, 2009.

[7] H. I. Abdel-Shafy and M. S. M. Mansour, "Green synthesis of metallic nanoparticles from natural resources and food waste and their environmental application," Green Metal Nanoparticles, vol. 117, pp. 321-385, 2018.

[8] M. Skiba, V. Vorobyova, O. Pivovarov et al., “"Green” synthesis of nanoparticles of precious metals: antimicrobial and catalytic properties," Eastern-European Journal of Enterprise Technologies, vol. 2, pp. 51-58, 2018.

[9] M. Sardarodiyan and A. Mohamadi Sani, "Natural antioxidants: sources, extraction and application in food systems," Nutrition \& Food Science, vol. 46, no. 3, pp. 363-373, 2016.

[10] N. Jorge, C. M. Veronezi, D. C. Pereira, and C. Pereira, "Extracts of red peppers: antioxidant activity and sensory evaluation," Nutrition \& Food Science, vol. 46, no. 2, pp. 228-236, 2016.

[11] V. Vorob'iova, O. Chyhyrynets, and O. Vasyl'kevych, "Mechanism of formation of the protective films on steel by volatile compounds of rapeseed cake," Materials Science, vol. 50, no. 5, pp. 726-735, 2015.

[12] O. Chyhyrynets' and V. Vorob'iova, “Anticorrosion properties of the extract of rapeseed oil cake as a volatile inhibitor of the atmospheric corrosion of steel," Materials Science, vol. 49, no. 3, pp. 318-325, 2013.

[13] V. Vorobyova, M. Skiba, and O. Chygyrynets', “A novel ecofriendly vapor phase corrosion inhibitor of mild steel," Pigment \& Resin Technology, vol. 48, no. 2, pp. 337-349, 2018.

[14] P. D. Drogoudi, S. Vemmos, G. Pantelidis, E. Petri, C. Tzoutzoukou, and I. Karayiannis, "Physical characters and antioxidant, sugar, and mineral nutrient contents in fruit from 29 apricot (Prunus armeniaca L.) cultivars and hybrids," Journal of Agricultural and Food Chemistry, vol. 56, no. 22, pp. 10754-10760, 2008.

[15] D. Cheaib, N. El Darra, H. Rajha, I. El-Ghazzawi, R. Maroun, and N. Louka, "Effect of the extraction process on the biological activity of lyophilized apricot extracts recovered from apricot pomace," Antioxidants, vol. 7, no. 1, pp. 11-32, 2018.

[16] A. A. M. Botterweck, H. Verhagen, R. A. Goldbohm, J. Kleinjans, and P. A. van den Brandt, "Intake of butylated hydroxyanisole and butylated hydroxytoluene and stomach cancer risk: results from analyses in The Netherlands cohort study," Food and Chemical Toxicology, vol. 38, no. 7, pp. 599-605, 2000.

[17] N. Balasundram, K. Sundram, and S. Samman, "Phenolic compounds in plants and agri-industrial by-products: antioxidant activity, occurrence, and potential uses," Food Chemistry, vol. 99, no. 1, pp. 191-203, 2006.

[18] E. Yara-Varón, A. S. Fabiano-Tixier, M. Balcells, R. CanelaGarayoa, A. Bily, and F. Chemat, "Is it possible to substitute hexane with green solvents for extraction of carotenoids? A theoretical versus experimental solubility study," RSC Advances, vol. 6, no. 33, pp. 27750-27759, 2016.

[19] K. K. Chew, M. Z. Khoo, S. Y. Ng et al., "Effect of ethanol concentration, extraction time and extraction temperature on the recovery of phenolic compounds and antioxidant capacity of Orthosiphon stamineus extracts," International Food Research Journal, vol. 18, pp. 1427-1435, 2011.

[20] A. Nikousaleh and J. Prakash, "Effect of dry heat treatment of six spices on antioxidant activity of their spice extracts," Foods, vol. 2, pp. 139-144, 2008. 
[21] M. Asghar, J. Akhtar, M. Shafiq et al., "GC-MS and antioxidant capacity analyses of cowpea seeds oils," Nutrition \& Food Science, vol. 43, no. 2, pp. 116-127, 2013.

[22] T. Rajan and S. Muthukrishnana, "Characterization of phenolic compounds in Pseudarthria viscida root extract by HPLC and FT-IR analysis," Asian Journal of Pharmaceutical and Clinical Research, vol. 6, no. 2, pp. 271-273, 2013.

[23] O. Benavente-Garcia, J. Castillo, J. Lorente et al., "Antioxidant activity of phenolics extracted from Olea europaea L. leaves," Food Chemistry, vol. 68, no. 4, pp. 457-462, 2000.

[24] E. Chan, Y. Lim, and M. Omar, "Antioxidant and antibacterial activity of leaves of Etlingera species (Zingiberaceae) in Peninsular Malaysia," Food Chemistry, vol. 104, no. 4, pp. 1586-1593, 2007.

[25] P. Prieto, M. Pineda, and M. Aguilar, "Spectrophotometric quantitation of antioxidant capacity through the formation of a phosphomolybdenum complex: specific application to the determination of vitamin E," Analytical Biochemistry, vol. 269, no. 2, pp. 337-341, 1999.

[26] F. Odabasoglu, A. Aslan, A. Cakir et al., "Antioxidant activity, reducing power and total phenolic content of some lichen species," Fitoterapia, vol. 76, no. 2, pp. 216-219, 2005.

[27] P. Jayanthi and P. Lalitha, "DPPH scavenging assay of the solvent extracts and fractionates of Eichhornia crassipes (Mart.) Solms," Journal of Pharmacy Research, vol. 5, no. 2, pp. 946-948, 2012.

[28] K. Thaipong, U. Boonprakob, K. Crosby, L. Cisneros-Zevallos, and D. Hawkins Byrne, "Comparison of ABTS, DPPH, FRAP, and ORAC assays for estimating antioxidant activity from guava fruit extracts," Journal of Food Composition and Analysis, vol. 19, no. 6-7, pp. 669-675, 2006.

[29] P. Melgarejo, Á. Calín-Sánchez, Á. A. Carbonell-Barrachina et al., "Antioxidant activity, volatile composition and sensory profile of four new very-early apricots (Prunus armeniaca L.)," Journal of the Science of Food and Agriculture, vol. 94, no. 1, pp. 85-94, 2014.

[30] V. I. Vorobyova, M. I. Skiba, A. S. Shakun, and S. V. Nahirniak, "Relationship between the inhibition and antioxidant properties of the plant and biomass wastes extracts-a Review," International Journal of Corrosion and Scale Inhibition, vol. 8, no. 2, pp. 150-178, 2019.

[31] S. Bureau, D. Ruiz, M. Reich et al., "Application of ATR-FTIR for a rapid and simultaneous determination of sugars and organic acids in apricot fruit," Food Chemistry, vol. 115, no. 3, pp. 1133-1140, 2009.

[32] J. Srivastava, S. Kumar, and P. S. Vankar, "Correlation of antioxidant activity and phytochemical profile in native plants," Nutrition \& Food Science, vol. 42, no. 2, pp. 71-79, 2012.

[33] J. Srivastava and P. S. Vankar, "Principal phenolic phytochemicals and antioxidant property in Eucalyptus bark," Nutrition \& Food Science, vol. 42, no. 6, pp. 412-421, 2012.

[34] L. Yu, "Antioxidant properties of several tropical fruits: a comparative study," Food Chemistry, vol. 103, no. 3, pp. 1003-1008, 2008.

[35] S. Dudonné, X. Vitrac, P. Coutière, M. Woillez, and J. M. Mérillon, "Comparative study of antioxidant properties and total phenolic content of 30 plant extracts of industrial interest using DPPH, ABTS, FRAP, SOD, and ORAC assays," Journal of Agricultural and Food Chemistry, vol. 57, no. 5, pp. 1768-1774, 2009. 